\title{
ВНУТРЕННИЕ ПРЕДПОСЫЛКИ И ВНЕШНИЕ ФАКТОРЫ ВОЗВЕДЕНИЯ БЕРЛИНСКОЙ СТЕНЫ (1953-1961 гг.)
}

В статье на фоне послевоенных экономических трудностей в Германской Демократической Республике раскрывается рост социально-политической напряженности в восточногерманском обществе в период так называемого берлинского кризиса, кульминацией которого стало укрепление секторальной границы в Берлине. Решение о строительстве Берлинской стены автор объясняет не только глубокими противоречиями в германо-германских отношениях, обострившихся после образования двух немецких государств, но и ужесточением холодного идеологического противостояния между Западом и Востоком. Бывшие союзники по антигитлеровской коалиции, прежде всего, США и СССР, поделившие Европу на зоны влияния, стремились не только укрепить свои позиции в подконтрольных им го- сударствах, но и с помощью политико-дипломатических механизмов создать плацдармы для будущих баталий на фронтах «холодной войны». В силу этого они не смогли принять компромиссного решения по стабилизации обстановки в Восточном Берлине и определению статуса западной части города, а власти ГДР быстро воспользовались разногласиями в стане бывших союзников для кардинального решения проблемы бегства восточных немцев через секторальную границу на Запад посредством строительства бетонной стены вокруг Западного Берлина.

Ключевые слова: Берлинский кризис, Берлинская стена, оккупационные зоны, секторальная граница, восстание рабочих, бегство на Запад, союзники, Восточная Европа.

G. Rykun, T. Plokhotnyuk

\section{INTERNAL BACKGROUND AND EXTERNAL FACTORS FOR THE ESTABLISHMENT OF THE BERLIN WALL (1953-1961)}

Against the background of post-war economic difficulties in the German Democratic Republic, the article reveals the growth of socio-political tension in East German society during the so-called Berlin crisis, culminating in the strengthening of the sectoral border in Berlin. The author explains the decision to build the Berlin Wall not only by the deep contradictions in the German-German relations, aggravated after the formation of the two German states, but also by the tightening of the cold ideological confrontation between the West and the East. Former allies in the anti-Hitler coalition, primarily the United States and the USSR, who divided Europe into zones of influence, sought not only to strengthen their positions in the states controlled by them, but also, using political

У нескольких послевоенных поколений во всем мире «Берлинская стена» ассоциируется с идеологическим противостоянием между Западом и Востоком, а ее разрушение символизирует окончание «холодной войны». Данное утверждение вполне обосновано, хотя для самих немцев стена означала, прежде всего, раздел страны, общества, семей, который стал следствием поражения Германии в развязанной нацистским правительством Третьего рейха Второй мировой войне. В массовом сознании немцев стена воспринималась как символ утраты могущества, национального унижения, политической и экономической самостоятельности. Надежды на их возрождение были, но они вступали в противоречие с недав- and diplomatic mechanisms, to create bridgeheads for future battles on the fronts of the Cold War. Because of this, they could not make a compromise decision to stabilize the situation in East Berlin and determine the status of the western part of the city, and the GDR authorities quickly took advantage of the disagreements in the camp of the former allies to radically solve the problem of the flight of East Germans across the sectoral border to the West through the construction of a concrete wall around the West Berlin

Key words: Berlin crisis, Berlin Wall, occupation zones sectoral border, workers' uprising, flight to the West, allies, Eastern Europe.

ним нацистским прошлым, от которого сложно было отказаться или предать забвению.

Как известно, в 1945 г. на Потсдамской конференции союзники по антигитлеровской коалиции поделили побежденную Германию на четыре оккупационные зоны. Договориться о статусе Берлина, большая часть которого находилась под контролем советских войск, союзникам так и не удалось. В середине 1950-х гг. США, Великобритания и Франция отклонили предложение советского руководства о придании германской столице статуса свободного демилитаризованного города, в результате чего его постигла участь страны: Берлин также был разделен на Западную 
и Восточную части и превратился в центр идеологического противоборства в Европе.

В мае и октябре 1949 г. на карте европейского континента появились два немецких государства Федеративная Республика Германии (ФРГ) и Германская Демократическая Республика (ГДР). Столицей ФРГ был провозглашен Бонн, а столицей ГДР стала Восточная часть Берлина. Население ФРГ и ГДР вплоть до окончания Второй мировой войны представляло собой единую национальную общность с собственной этнической идентичностью, менталитетом, культурными и мировоззренческими ценностями. Война, развязанная нацистами, поделили это общество на две части без учета интересов и убеждений, социальной и политической ориентации. В этой связи по обе стороны германо-германской границы находились как сторонники, так и противники установленных режимов [2, с. 157-160].

Восточная Германия (ГДР) столкнулась с большими трудностями восстановления разрушенной страны на основе плановой экономики, ситуацию усугубляла необходимость репарационных выплат победителям. В стране не хватало продовольствия, действовала карточная система социальная инфраструктура восстанавливалась медленными темпами, заработная плата на государственных предприятиях была низкой, а уровень безработицы не позволял строить планы на будущее. К тому же, в силу понятных причин, со стороны оккупационных властей в рамках политики денацификации действовали многочисленные, а порой жесткие ограничительные меры. Со временем совокупность негативных тенденций послевоенного развития восточногерманского общества вынуждала людей вступать на путь протеста, одной из форм которого явилось бегство на Запад.

В это же самое время благополучные и вышедшие из войны с минимальными потерями Соединенные Штаты Америки установили на территории Западной Германии (ФРГ) либеральный режим, они щедро снабжали Западную Германию товарами первой необходимости. Уровень жизни населения повышался, сокращалась безработица, что, естественно, привлекало восточных немцев. На Запад бежала в основном трудоспособная часть населения, профессиональные специалисты, инженерно-технический персонал крупных промышленных предприятий. Вследствие этого на Востоке страны прекратили свое существование многие заводы и фабрики, например, заводы Германского автомобильного союза (Auto Union), позднее они возобновили свою деятельность в Западной Германии, создав концерн «Ауди» $[4$, с. 98].

В июне 1953 года волна недовольства в ГДР вылилась в открытое противостояние с властью Поводом послужило официальное сообщение правительства и ЦК правящей Социалистической единой партии Германии (СЕПГ) о решении повысить нормы выработки на предприятиях без увеличения заработной платы якобы по просьбе трудящихся и в целях борьбы с экономическими трудностями. Вышедшие на улицу возмущенные рабочие выдвигали не только экономические (повышение заработной платы, снижение цен и норм выработки), но и политические требования об устранении границ и выводе оккупационных войск.

Бывшие союзники по антигитлеровской коалиции в Западных зонах оккупации Германии не только пристально контролировали развитие событий в Берлине, но и пытались оказать на ситуацию деструктивное воздействие, направить сознание протестующих в русло углубления конфликта с властью, вовлечения в протест более широких слоев населения в других регионах ГДР Это им удалось, многотысячные демонстрации состоялись во всех крупных городах и промышленных центрах Восточной Германии. Особая активность в разжигании страстей, создании провокационных ситуаций наблюдалась со стороны популярной в то время радиостанции RIAS (Rundfunk im amerikanischen Sektor - Радио американского сектора). Радиостанция располагалась на территории Западного Берлина, а ее деятельность была целиком и полностью подчинена идеологическому воздействию на умы и сознание простых граждан посредством распространения в их среде альтернативной, чаще всего тенденциозно подобранной информации о положении дел В ГДР на фоне процветания и укрепления ФРГ.

Анализируя события тех лет, современные аналитики вполне обоснованно считают, что возведение «Берлинской стены» отчасти являлось реакцией на политтехнологии этого противоборства, которые использовались Западом для снижения международного авторитета, созданной Советским Союзом социалистической системы. ГДР оказалась на передовых позициях идеологической борьбы между Западом и Востоком.

Власти Западных оккупационных властей, стремясь показать свою приверженность межсоюзническим договоренностям, широко распространяли информацию о мерах по сдерживанию рабочих Западного Берлина, намеревавшихся оказать поддержку своим восточногерманским коллегам, по предотвращению попыток распространения письменных обращений к советским военнослужащим с призывами к сдержанности и неприменению силы к протестующим. Подобные материалы оказывали выгодное, ожидаемое Западом воздействие, еще сильнее накаляли обстановку в ГДР. Они становились катализатором новых протестных акций, в общей сложности в них приняло участие порядка одного миллиона жителей Восточной Германии.

Июньское восстание 1953 года в ГДР было подавлено с помощью советских воинских частей, в стране сменилось партийное руководство, была удовлетворена часть требований протестующих о снижении цен и норм выработки, по результатам многочисленных расследований и судебных процессов в стране появилась такая категория граждан как политзаключенные. Около двух тысяч 
немцев лишились свободы на длительные сроки. Среди пострадавших числятся и советские военнослужащие, которые отказывались стрелять по безоружным протестующим. Жители Западного Берлина в знак благодарности установили им в Целендорфе памятный камень [3].

С течением времени общественно-политическая ситуация в ГДР вошла в русло повседневных социально-экономических забот, отмечалось даже повышение уровня лояльности простого народа к власти. Германская Демократическая Республика, начиная с 1953 г., демонстрировала реальные успехи экономического роста в соревновании с ФРГ и в конце 1950-х гг. прочно занимала место в пятерке экономически развитых государств Европы. Однако полностью справиться с проблемой бегства граждан ГДР в Западный Берлин не удавалось вплоть до начала 1960-х гг За этот период из Восточного Берлина бежало около двух миллионов человек, список погибших, по данным разных источников, содержит от 645 до 1245 имен (Би-Би-Си), документально подтверждена гибель 140 человек, почти в три раза больше арестованных и осужденных за попытку нелегального пересечения границы внутри города. Уголовный кодекс ГДР предусматривал за это 10 лет лишения свободы. По имеющимся данным, в течение двух лет после подавления берлинского восстания ГДР нелегально покинуло более 300 тысяч человек [8]

Именно с учетом этих данных мы предпочитаем рассматривать проблему возведения Берлинской стены в рамках Берлинского кризиса, который охватывает наиболее напряженный период «холодной войны» в центре Европы. Четких временных границ этот период не имеет. Одни исследователи рассматривают его в рамках 19581961 гг., другие раздвигают эти рамки до 1963 г., когда советское руководство фактически отказалось от намерения заключать мирный договор с ГДР, а с гражданским правительством Западного Берлина было достигнуто соглашение о порядке пересечения внутригородской границы. По нашему мнению, если брать во внимание появление Берлинской стены как апогея кризиса между бывшими союзниками и двумя германскими государствами, то предпочтительней обращение к более длительному периоду, начиная с 1953 г., когда нестабильная обстановка в Восточной Германии вызывала серьезные опасения мировой общественности и могла негативно отразиться на решении всей германской проблемы. Это со всей очевидностью показали описанные выше события лета 1953 г.

В то же время на глубину кризисных проявлений в Берлине в 1950 - начале 1960-х гг. оказывали влияние не только внутригерманские противоречия, но внешние фракторы, обусловленные политико-дипломатическим противостоянием между СССР и бывшими союзниками по антигитлеровской коалиции, прежде всего США. Американская позиция на тот период времени заключалась в создании единого германского государства посредством включения ГДР в состав ФРГ, возрождении бундесвера и размещении в Западной Германии американских ракет с атомными боеголовками. В ответ на эти плань советское руководство высказало намерение подписать, по сути, сепаратный мирный договор с ГДР. В этом случае весь Берлин оказался бы на территории суверенной Германской Демократической Республики, а союзникам пришлось бы вывести из города свои воинские подразделения. ГДР такой договор вполне устраивал, поскольку он укреплял ее государственный статус, создавал перспективу распространения влияния на западную часть Берлина и позволял решать проблему исхода населения [5, с. 13-19].

Однако быстро подписать мирный договор с ГДР Советский Союз не мог, хотя проект уже был готов. Правительство СССР в конце 1950-х гг. было ограничено в действиях другими межсоюзническими соглашениями и наметило подписание договора на декабрь 1961 года [9, с. 87-98]. Взятая отсрочка давала возможность проследить отношение Запада и в случае необходимости принять меры по локализации назревавшего конфликта, который мог перерасти в военное противостояние. Западные державы, в свою очередь, также заняли выжидательную позицию, постоянно затягивая переговоры с СССР для выработки взаимоприемлемого решения [1, с. 425-426]

Западная позиция не осталась незамеченной общественностью ФРГ, которая высказывала претензии по поводу того, что США, Великобритания и Франция в своих политических планах игнорируют вопрос объединения Германии даже в отдаленной перспективе. По инициативе немецких социал-демократов к дискуссии по этому поводу была привлечена ООН и ряд других международных организаций. В результате под давлением международного общественного мнения западные державы пошли на некоторые уступки, согласившись с необходимостью соблюдать разумную достаточность свободы пересечения внутригородской границы и возможностью предоставлять восточным немцам рабочие места в Западном Берлине [6, с. 382]. Но, для властей ГДР это было заведомо неприемлемое решение, не устраивало оно и советское руководство. В то же время стало понятно, что союзники не имеют определенного плана развития ситуации в Германии и в Берлине, в частности, и вряд ли будут решительно противодействовать радикальным мерам со стороны восточногерманских властей. К тому же они были не готовы, ради укрепления позиций в Западном Берлине, рисковать утратой влияния в Европе и других регионах мира. Это отчетливо показала очередная встреча министров иностранных дел США, Великобритании и Франции в Париже в начале августа 1961 г.

Что касается позиции советского правительства в отношении Берлинского кризиса, то она также не была однозначной. Москва проявляла озабоченность по поводу увеличения случаев бегства восточных немцев на Запад, но ее в боль- 
шей мере волновали более масштабные проблемы всей Восточной Европы. В такой ситуации когда все союзнические державы избрали тактику осторожного воздействия на обстановку в Берлине, дабы не вызвать негативную реакцию друг друга, власти ГДР действовали решительно. На очередном совещании партийных руководителей стран Восточной Европы они получили их согласие на ужесточение пограничного режима в Берлине, и в ночь с 12 на 13 августа 1961 г. граница была полностью закрыта сначала живой цепью пограничников и полицейских, а через несколько дней - бетонными заграждениями и колючей проволокой

В Восточной Германии Берлинская стена официально называлась Антифашистский защитный вал (Antifaschistischer Schutzwall), в Западной Германии она воспринималась, как стремление советской зоны оккупации огородиться от внешнего мира. За время своего существования в течение 28 лет стена претерпела множество реконструкций и, в конце концов, из небольшого участка колючей проволоки внутри Берлина превратилась в мощный 155-ти кМ военно-инженерный комплекс, оснащенный сигнальным оборудованием, видеонаблюдением, контрольно-пропускными пунктами, сторожевыми вышками и другими пограничными сооружениями со средней высотой заграждений - 3,5 метра. В наиболее уязвимых местах стена была укреплена параллельными железобетонными блоками, между которыми была оборудована контрольно-следовая полоса и протянуто проволочное заграждение под электрическим напряжением. Лица, попадавшие в эту зону, обрекали себя на верную гибель, так как пограничники ГДР, начиная с 1973 г., беспрекословно выполняли приказ открывать огонь на поражение по нарушителям границы без предупреждения [7, с. 35-38]. В любом случае, это было единственное заграждение в истории мировых конфоликтов, которое строилось не для противодействия внешним угрозам, а для сдерживания собственных граждан от бегства из страны.

Западные державы, в целом, спокойно восприняли известие о закрытии секторальной границы в Берлине, если не считать отдельных инциден- тов, например, «танкового противостояния» в районе пропускного пункта «Чарли». Сутки американские и советские танки стояли друг против друга в полной боевой готовности, но тогда разум восторжествовал над эмоциями. Первыми место противостояния покинули советские танки, вслед за ними и американцы вернули свои боевые машины в места постоянной дислокации. На этом конфликт был исчерпан. Западные державы также были заинтересованы в сокращении численности беженцев, которых нужно было принимать, обустраивать, обеспечивать рабочими местами, социальными пакетами и т.д. В то время западные державы из двух зол выбрали наименьшее, им было леге согласиться с ужесточением пограничного режима между секторами, чем утратить свои позиции в Западном Берлине. Этот город, расположенный внутри ГДР и социалистического блока, нужен был им для реализации дальнейших планов борьбы с Советским Союзом. В Западном Берлине была создана самая крупная в Европе резидентура ЦРУ, располагались так называемые миссии связи при главнокомандующих союзнических войсках, полностью состоявшие из кадровых военных разведчиков, активно действовали такие известные антисоветские пропагандистские центры, как Би-Би-Си, Радио Свобода, Голос Америки, радиостанции американской, английской и французской комендатур, западногерманская радиостанция Радио-100 и многие другие. Свои позиции в Западном Берлине бывшие союзники по антигитлеровской коалиции сохранили, несмотря на многомиллионные расходы, связанные с достижением и реализацией торговых, транспортных и других соглашений с Восточногерманскими властями и советской военной администрацией в ГДР

Остается добавить, что Берлинской стены могло не быть, если бы советское руководство того периода проявило бы настойчивость в решении административно-территориальных и других вопросов обустройства послевоенной Германии и не форсировало бы перевод восточногерманской экономики на рельсы планового развития, как предлагали некоторые члены правительства, обвиненные позднее в измене Родине и объявленные врагами народа.

\section{Источники и литература}

1. Бейли Дж., Кондрашев С., Мерфи Д. Поле битвы - Берлин. ЦРУ против КГБ в холодной войне; пер. с англ. Л. Володарской. М.: ЭКСМО, 2002. $541 \mathrm{c.}$

2. Ватлин А. Ю. Германия в XX веке. М.: РОССПЭН, 2002. $336 \mathrm{c}$.

3. Восстание рабочих в ГДР (16-17 июня 1953 г.) URL: https://rusidea.org/25061708 (Дата обращения: 21.09.2019).

4. Невский С. И. Экономика послевоенной Западной Германии: на пути к «экономическому чуду». М.: МГУ-ТЕИС, 2006. $168 \mathrm{c}$

5. Платошкин Н. Н. Предыстория возведения Берлинской стены. Август 1961 года // Военно-исторический журнал. 2009. №1. C. 13-19.

6. Рыкун Г. Н. Восточноевропейская политика Советского Союза в контексте решения «германского вопроса». 1941-1961. Ростов-на-Дону: СКНЦвШ, 2005. 428 с.

7. Славин А. Защитный вал диктатуры // Новое время. 2011. 8 августа. №24(209). С. 35-38.

8. 140 человек погибли при попытках преодолеть Берлинскую стену URL: https://www. svoboda. org/a/ 28669912.html (Дата обращения: 21.09.2019).

9. Foreign Relations of the United States (FRUS). 1961-1963. Vol.13. Wash., 1969. 455 p. 


\section{References}

1. Bejli Dzh., Kondrashev S., Merfi D. Pole bitvy - Berlin. CRU protiv KGB v holodnoj vojne (Battlefield - Berlin. CIA vs. $K G B$ in Cold War) / per. s angl. L. Volodarskoj. Moscow: EKSMO publ., 2002. 541 p. (In Russian)

2. Vatlin A. Yu. Germaniya v XX veke (Germany in the Twentieth Century). Moscow: ROSSPEHN publ., 2002. 336 p. (In Russian)

3. Vosstanie rabochih v GDR (16-17 iyunya $1953 \mathrm{~g}$.) (Rise of the workers in the GDR (June 16-17, 1953) URL: https:// rusidea.org/25061708 (Accessed: 21.09.2019). (In Russian)

4. Nevskij S. I. Ekonomika poslevoennoj Zapadnoj Germanii: na puti k «ekonomicheskomu chudu» (The Economics of Post-War West Germany: Towards an "Economic Miracle"). Moscow: MGU- TEIS publ., 2006. 168 p. (In Russian)

5. Platoshkin N. N. Predystoriya vozvedeniya Berlinskoj steny. Avgust 1961 goda (Background to the construction of the Berlin Wall. August 1961) // Voenno-istoricheskij zhurnal. 2009. No. 1. P. 13-19. (In Russian)

6. Rykun G. N. Vostochnoevropejskaya politika Sovetskogo Soyuza v kontekste resheniya "germanskogo voprosa» 1941-1961 (Eastern European policy of the Soviet Union in the context of solving the "German question». 1941-1961) Rostov-na-Donu: SKNCVSH publ., 2005. 428 p. (In Russian)

7. Slavin A. Zashchitnyj val diktatury (Protective shaft of dictatorship) // Novoe vremya. 2011. August 8. No. 24(209) P. 35-38.

8. 140 chelovek pogibli pri popytkah preodolet' Berlinskuyu stenu ( 140 people died while trying to overcome the Berlin Wall) URL: https://www. svoboda. org/a/ 28669912.html (Accessed: 21.09.2019) (In Russian)

9. Foreign Relations of the United States (FRUS). 1961-1963. Vol. 13. Wash., 1969. 455 p.

\section{Сведения об авторах}

Рыкун Галина Николаевна - доктор исторических наук, профессор кафедры туризма и гостиничного дела Северо-Кавказского фредерального университета (филиал в г. Пятигорске) / galina.rykun@gmail. com

Плохотнюк Татьяна Николаена - доктор исторических наук, профессор кафедры истории России гуманитарного института Северо-Кавказского фредерального университета (Ставрополь) / plokhotnjuk@ gmail.com

\section{Information about the authors}

Rykun Galina - Doctor of Historical Sciences, Professor, Chair of Tourism and Hospitality, North-Caucasus Federal University (branch in Pyatigorsk) / galina.rykun@gmail.com

Plokhotnyuk Tat'yana - Doctor of Historical Sciences, Professor, Chair of Russian History, Institute of Humanities, North-Caucasus Federal University (Stavropol) / galina.rykun@gmail.com 